\title{
High Touch Surface COVID-19 Cleaning and Disinfecting: Workforce Health and Safety Preparation
}

By Skiba, Richard

Abstract- This paper reviews the current accepted practice for high touch surface cleaning and disinfection to kill surface COVID-19 virus such that transmission risks are lowered. Surface cleaning and disinfecting is considered from a workplace perspective, in a non-healthcare setting, and an outline of a worker training program is developed to align with the noted best practices. The program overview presented is based on a competency-based framework and designed in a way such that it can be customised to required environmental circumstances. A practical health and safety training program application is outlined, showcasing adaptation in vocational education and training sector to a current context.

Keywords: COVID-19, cleaning, disinfecting, health and safety, vocational education.

GJMR-K Classification: NLMC Code: WA 240

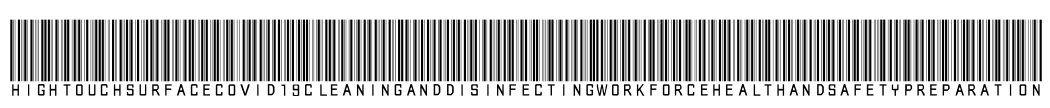

Strictly as per the compliance and regulations of:

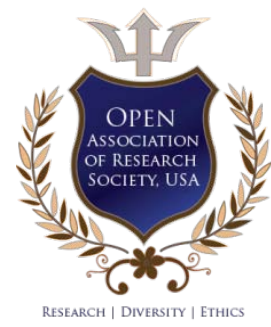

(c) 2020. Skiba, Richard. This is a research/review paper, distributed under the terms of the Creative Commons AttributionNoncommercial 3.0 Unported License http://creativecommons.org/licenses/by-nc/3.0/), permitting all non-commercial use, distribution, and reproduction in any medium, provided the original work is properly cited. 


\title{
High Touch Surface COVID-19 Cleaning and Disinfecting: Workforce Health and Safety Preparation
}

\author{
Skiba, Richard
}

\begin{abstract}
This paper reviews the current accepted practice for high touch surface cleaning and disinfection to kill surface COVID-19 virus such that transmission risks are lowered. Surface cleaning and disinfecting is considered from a workplace perspective, in a non-healthcare setting, and an outline of a worker training program is developed to align with the noted best practices. The program oveniew presented is based on a competency-based framework and designed in a way such that it can be customised to required environmental circumstances. A practical health and safety training program application is outlined, showcasing adaptation in vocational education and training sector to a current context.

Keywords: COVID-19, cleaning, disinfecting, health and safety, vocational education.
\end{abstract}

\section{INTRODUCTION}

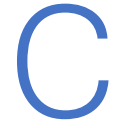
OVID-19 is a respiratory illness caused by a novel (or new) coronavirus that has not previously been seen in humans that produces a range of symptoms from a mild cough to pneumonia (Queensland Government, 2020; Centers for Disease Control and Prevention, 2020a). While some people recover easily, others may get very sick very quickly, and there is evidence that it spreads from person to person. In COVID-19, 'CO' stands for 'corona,' 'VI' for 'virus,' and 'D' for disease and is caused by a coronavirus called SARS-CoV-2 (Centers for Disease Control and Prevention, 2020a). Since there are no standard treatments for COVID-19, it is imperative to avoid infection or further spreading ( $\mathrm{Wu}$, Chen and Chan, 2020).

The Centers for Disease Control and Prevention (2020a) advise that the virus is thought to spread mainly from person to person, primarily through respiratory droplets produced when an infected person coughs or sneezes. They inform that the droplets can land in the mouths or noses of people who are nearby or possibly be inhaled into the lungs. They also suggest that spread is more likely when people are in close contact with one another, which they state is within about 6 feet or approximately 1.8 meters. The virus may spread effortlessly and sustainably in a community, referred to as community transmission, resulting in many infections within a specific geography, whether this is a workplace,

Author: Director, LRES Training Management, Melbourne, Australia. e-mail: richard@skiba.com.au communal location or municipality. Fauci, Lane and, Redfield (2020) note that the efficiency of transmission for any respiratory virus has significant implications for containment and mitigation strategies. Aside from social distancing, environmental controls such as effective cleaning and disinfection contribute to mitigation strategies. Reducing the risk of exposure to COVID-19 by cleaning and disinfection is, in particular, an important part of reopening public spaces.

Regarding surfaces and objects, Centers for Disease Control and Prevention (2020a) state that "It may be possible that a person can get COVID-19 by touching a surface or object, like a packaging container, that has the virus on it and then touching their own mouth, nose, or possibly their eyes, but this is not thought to be the main way the virus spreads". The Queensland Government (2020) states that touching objects or surfaces contaminated by cough or sneeze droplets from a person with COVID-19 infection, and then touching the mouth or face can result in the virus spreading. By killing germs on a surface after cleaning, the risk of spreading the virus is lowered (Centers for Disease Control and Prevention, 2020a). Disinfectants kill germs on surfaces and killing germs on a surface after cleaning, lowers the risk of spreading infection.

Public Health England (2020) advises that the risk of infection depends on many factors and, these include the type of surfaces contaminated, the amount of virus shed from the individual, the time the individual spent in the setting, and the time since the individual was last in the setting. European Centre for Disease Prevention and Control (2020) notes that "the environmental stability of SARS-CoV-2 is up to three hours in the air post-aerosolisation, up to four hours on copper, up to 24 hours on cardboard and up to two to three days on plastic and stainless steel, albeit with significantly decreased titres [concentration]".

As a general approach, workplaces should clean surfaces at least daily with special attention given to frequently touched surfaces (Safe Work Australia, 2020). These surfaces, as examples, can include but are not limited to light switches, tabletops, door handles, handrails, desks, toilets, taps, kitchen surfaces, and cupboard handles. Ideally, once clean, surfaces should also be disinfected regularly. The surfaces should be cleaned more frequently when they are visibly soiled, 
used repeatedly by several people or after any spillage. As an example, items such as trolleys, retail checkouts, and EFTPOS machines must be cleaned more frequently due to their high use.

Safe Work Australia (2020) outlines, "when and how often a workplace should undertake disinfection as part of routine cleaning will depend on the likelihood of contaminated material being present at the workplace". They suggest by way of example, in a busy retail environment with many customers and others entering a workplace each day, disinfecting must occur more frequently to prevent the spread of COVID-19. The Centers for Disease Control and Prevention (2020a) advise that cleaning and disinfection should be performed by cleaning staff who are trained on the appropriate use of cleaning and disinfection chemicals and provided with the personal protective equipment (PPE) required for the chemicals used. Personal protective equipment is used to reduce the risk of direct contact with contaminated surfaces.

Two critical aspects are of fundamental requirements for training those workers who are responsible for cleaning and disinfection to remove COVID-19, namely the safety of the worker performing the cleaning activity and the effective removal of the virus from the high touch surface such that there is no opportunity for contact infection.

\section{il. Method}

The study is based on a review of primarily of published research and government or government body published findings with respect to COVID-19 cleaning and disinfecting such that best practice can be determined and qualified for training purposes. A broad scope of literature is addressed to establish consensus in processes and these are noted as a baseline for determination of competence for an individual tasked with the responsibility for cleaning and disinfecting high touch surfaces in a non-healthcare setting, such as retail and other workplace environments. As a limitation to the study, it does not aim to produce specialists but rather outline best practices in terms of content for inclusion in a training program.

\section{ili. Discussion}

Safe Work Australia (2020) defines both cleaning and disinfection, stating that "cleaning means physically removing germs, dirt and organic matter from surfaces". Disinfecting, on the other hand, refers to "using chemicals to kill germs on surfaces. It's important to clean before disinfecting because organic matter and dirt can reduce the ability of disinfectants to kill germs".

In terms of managing COVID-19 in a workplace context, Safe Work Australia advises that a utilizing a combination of both cleaning and disinfection is the most effective way to remove the virus. The cleaning process will reduce the soil load on the high touch surface such that the disinfectant can work to effectively kill the COVID-19 virus. Where the surface is not suitably prepared by cleaning with a detergent first, the disinfectant may not kill the virus.

\section{a) Cleaning Risks and Contro/s}

The Australian Department of Health notes that the risk when cleaning or disinfecting is not the same as the risk when face-to-face with a sick person who may be coughing or sneezing (Department of Health, 2020). To manage the risks associated with cleaning, cleaning staff should be advised to avoid touching their face, especially their mouth, nose, and eyes when cleaning. Utilization of Personal Protective Equipment (PPE) is also critical as a risk control measure, including using impermeable disposable gloves and a surgical mask plus eye protection or a face shield while cleaning. Competent use of PPE is an essential founding component of a training program in COVID-19 Cleaning and Disinfection. As a preparatory exercise before undertaking the cleaning, cleaners should use alcoholbased hand rub before putting on and after removing gloves and, likewise, the hand rub should also be used before putting on and after removing the surgical mask and eye protection.

The Department of Health (2020) advise that cleaners should be aware that surgical mask and eye protection act as barriers to people inadvertently touching their face with contaminated hands and fingers, whether gloved or not. They also note that where there is visible contamination on the surface to be cleaned, such as respiratory secretions or other body fluid, the cleaners should wear a full-length disposable gown in addition to the surgical mask, eye protection and, gloves. All PPE needs to be utilized and correctly fitted in accordance with the relevant manufacturer's instructions, including the corresponding Safety Data Sheet (SDS), and in line with employer policies and procedures. Use of PPE is instrumental in protecting cleaning workers and preventing the spread of COVID19 and, the World Health Organization recommends staff training on the use of PPE, including masks, doffing procedures, and hand hygiene practices (World Health Organization, 2020).

Training programs should include accessing and reading Safety Data Sheets including correct processes for transporting, storing, handling and disposing of chemicals, cleaning up skills, applying first aid and the hierarchy of controls.

\section{b) Use of Disinfectants}

Wu, Chen and Chan (2020), as proposed by the National Environment Agency, Singapore, outline that COVID-19 is susceptible to many active ingredients, including sodium hypochlorite $(0.1 \%-0.5 \%), 70 \%$ ethyl alcohol, povidone-iodine (1\% iodine), chloroxylenol $(0.24 \%), \quad 50 \%$ isopropanol, $0.05 \%$ benzalkonium 
chloride, $1 \%$ cresol soap, or hydrogen peroxide $(0.5 \%-$ 7.0\%), amongst others. Disinfectants containing greater than or equal to $70 \%$ alcohol, quaternary ammonium compounds, chlorine bleach, or oxygen bleach are suitable for use on hard surfaces (Safe Work Australia (2020).

The American Chemistry Council's (ACC) Center for Biocide Chemistries (CBC) has compiled a list of products that have been approved by the U.S. Environmental Protection Agency (EPA) for use against emerging enveloped viral pathogens and can be used during the current novel coronavirus (COVID-19) outbreak (Center for Biocide Chemistries (2020). The list includes ready-to-use sprays, concentrates, and wipes. This list, known as 'List N: Disinfectants for Use Against SARS-CoV-2' and available at https://www.epa.gov/ pesticide-registration/list-n-disinfectants-use-against-

sars-cov-2, provides an in-depth list of chemical applications and should be included in training for cleaning workers such that they can correctly identify and apply the most suitable chemicals for cleaning and disinfection.

\section{c) Preparation of Chlorine-Based Disinfectant Solution}

Chlorine is an effective killer of viruses, however, it should be noted that it can be hazardous for humans, and as such, where possible, safer alternatives should be used. These should be prepared in the correct concentrations with dilutions based on the manufacturer's instructions. During preparations, the concentrate should be added to water rather than water to the concentrate. Diluting solutions is a core component of a training program for cleaners of high touch surfaces, as is their correct use. In terms of their use, they should be applied using PPE, in well-ventilated areas, and not mixed with any other products (Department of Health, 2020). Chlorine solutions should be made up daily and used mainly on hard, non-porous surfaces as it can damage textiles and metals. The Western Australian Department of Health advises avoiding 'topping up' detergent or disinfectant containers as this can lead to contamination of the containers.

\section{d) Cleaning and Disinfection Processes}

Queensland Government (2020) recommends that hard surfaces can be cleaned by performing a physical clean using a combined detergent and 1,000ppm bleach solution (2-in-1 clean) made up daily from a concentrated solution. As an alternative, they provide applying a physical clean using detergent and water followed by a clean with 1,000ppm bleach solution (2-step clean), for example, household bleach or hospital-grade bleach solutions that are readily available from retail stores. Household bleach comes in a variety of strengths of the active ingredient, sodium hypochlorite, and this information is located on the product label, often listed as available chlorine. The manufacturer's directions for dilution should always be followed.

Public Health England (2020) advocates the use of disposable cloths or paper roll and disposable mop heads, to clean all hard surfaces, floors, chairs, door handles and sanitary fittings, following one of the options: use either a combined detergent disinfectant solution at a dilution of 1,000 parts per million available chlorine; or, a household detergent followed by disinfection (1000 ppm av.cl.). Follow manufacturer's instructions for dilution, application and, contact times for all detergents and disinfectants; or, if an alternative disinfectant is used within the organization, this should be checked and ensure that it is effective against enveloped viruses. The Centre for Health Protection, Hong Kong, suggest areas with frequent access by members of the public, such as lifts, escalators, lobby entrance, waiting areas, corridors, information counters and, lounges should be leaned and wiped at least twice daily. For frequently touched surfaces such as buttons, handrails, handle, chairs and mailboxes), these should be cleaned and wiped at least twice daily and when visibly soiled. They also suggest cleaning the exhaust fan inside lifts regularly (Centre for Health Protection, 2020).

Training should also provide the knowledge and skills necessary to identify the surfaces to be cleaned and disinfected and the most suitable methods to do so. Some surfaces only need to be cleaned with soap and water such as those that are not frequently touched. They should be cleaned and do not require additional disinfection (Centers for Disease Control and Prevention, 2020b). The Centers for Disease Control and Prevention also notes that disinfectants also should typically not be applied on items used by children, particularly any objects that children might put in their mouths as many disinfectants are toxic when swallowed. With regard to disinfection, each environment will have different surfaces and objects that are frequently touched by multiple people, and selection of the correct cleaning products and procedures is fundamental in their effectiveness, especially with soft and porous material or items like carpet, rugs, or seating in areas.

\section{e) Disposal or Cleaning of Materials and Personal Protective Equipment}

Cleaning equipment, including mop heads and cloths, should be laundered using hot water and entirely dried before re-use (Queensland Government, 2020). Cleaning equipment, such as buckets, should be emptied and cleaned with a new batch of chlorine bleach solution and allowed to dry completely before reuse. Safe Work Australia (2020) advises that reusable, washable cloths, PPE, and covers should be washed in a regular cycle wash using the warmest possible setting with normal washing detergent. These should not be 
shaken out before being placed in the washing machine. Disposable gloves should be worn to handle cloths, PPE, and covers, and workers should thoroughly wash their hands with soap and water for at least 20 seconds after removing the gloves (Safe Work Australia, 2020). The hamper used to store used PPE must also be regularly washed and, where it is not washable, a disposable lining should be utilized and replace consistently. Regarding reusable, non-washable PPE such as eye protection, these must be wiped clean with a detergent solution, then wiped over with a disinfectant. Once they are disinfected, they should be left to air dry.

Public Health England (2020) suggests that your waste should not be placed in communal waste areas until the waste has been stored for at least 72 hours.

\section{f) Vocational Education and Training Contexts}

Vocational education and training varies in its implementation from country to country. In some geographies, it is highly regulated and nationalized, in others, it is subject to accreditation, which may be compulsory or voluntary, and in some, there are no controls in place at all with training providers defining their own competency standards. For countries with developed competency standards, suitable competencies should be selected and customized to include COVID-19 cleaning and disinfection. Where no such standard or requirement applies, training providers should develop their programs around identified best practices. In either case, worker health and safety are the foundation on which the program should be constructed.

The Australian vocational education and training sector utilizes nationally recognized units of competency as a basis. Units of competency, where packed following packaging rules, can form qualifications that Registered Training Organisations can be registered to deliver. Individual units can also be added to a training provider's scope of registration. Within the range of units available within the national framework, the unit of competency 'CPPCLO3045 - Clean high-touch surfaces' from the CPP Property Training Package lends itself well as a basis for a training program for those providing cleaning for cleaning and disinfecting environments outside of a healthcare setting. The unit can be customized for the inclusion of cleaning and disinfecting with COVID-19 in mind.

Similarly, the New Zealand Qualifications Framework based unit standard '29389 Apply specialised knowledge of infection control and contamination prevention when working as a cleaner', outcomes can be utilized and adapted with COVID-19 cleaning and disinfecting content to develop a program for New Zealand based training providers. The City and Guilds unit 'Unit 111 Clean surfaces using correct methods' provides a basis for a training program for delivery in England, Wales, Scotland and Northern Ireland, for providers utilizing these standards.

Generally, vocational education and training systems are adaptable in a manner that facilitates contextualization, especially where health and safety are concerned. Training providers can use competency specifications to ensure that nationally agreed standards can be applied to the programs they deliver.

\section{g) Competency-Based Performance Criteria}

To successfully prepare workers engaged in high touch surface COVID-19 cleaning and disinfecting, the following performance criteria are proposed for inclusion in a competency-based program:

- Specific work requirements and instructions are obtained and interpreted.

- High touch surfaces and soil types are identified and assessed.

- Best practice COVID-19 cleaning techniques are identified.

- Best practice COVID-19 disinfecting techniques are identified.

- Required cleaning techniques are selected and confirmed.

- Work site hazards are identified.

- Risks associated with failing to follow infection control procedures are identified.

- Risks are controlled according to organizational, legislative, and health and safety requirements.

- Obtained and referred to Safety Data Sheets.

- Equipment is selected according to the area to be cleaned and/or disinfected and, checked for serviceability and cleanliness before use.

- Cleaning solutions are selected and prepared according to surface and soil to be cleaned and work requirements.

- Suitable known disinfectants for use against SARSCoV-2 are selected and prepared according to surface to be disinfected, and work requirements.

- Alcohol-based disinfectants (ethanol, propan-2-ol, propan1-ol) in concentrations of $70-80 \%$ are prepared.

- Tasks are sequenced following best practice and organizational procedures to ensure hygiene and efficiency in the completion of cleaning tasks.

- Personal protective equipment (PPE) is carefully chosen and used according to manufacturer specifications, and health and safety and organizational requirements.

- Loose soil and debris are removed from surfaces using required cleaning equipment and techniques.

- Required cleaning solution is applied to surfaces using correctly prepared cleaning equipment, and allowed to dwell according to manufacturer specifications. 
- Surfaces are rinsed free of residual cleaning solutions where required using selected equipment and techniques.

- Moisture is removed from surfaces and allowed to air dry according to task requirements.

- Required disinfecting solution is applied to surfaces using correctly prepared disinfecting equipment, and allowed to dwell with requisite exposure time.

- Unused cleaning solutions are stored or disposed of according to manufacturer specifications, and health and safety, and organizational requirements.

- Equipment and PPE are cleaned, safety checked, and stored or disposed of according to manufacturer specifications and environmental, health and safety, and organizational requirements.

\section{Conclusion}

Effective cleaning and disinfection of high touch surfaces is a significant contributor to minimizing the spread of COVID-19. To be performed effectively, recognized, and best practice techniques should be utilized, and the workers applying the cleaning and disinfecting must be adequately protected. A well laid out training program is essential for these workers.

\section{References Références Referencias}

1. Center for Biocide Chemistries. (2020). Novel Coronavirus (COVID-19) - Fighting Products. Retrieved from https://www.americanchemistry. com/Novel-Coronavirus-Fighting-Products-List.pdf.

2. Centers for Disease Control and Prevention. (2020a). Coronavirus Disease 2019 (COVID-19): Frequently Asked Questions. Retrieved from https:// www.cdc.gov/coronavirus/2019-ncov/faq.html.

3. Centers for Disease Control and Prevention. (2020b). Coronavirus Disease 2019 (COVID-19): Reopening Guidance for Cleaning and Disinfecting Public Spaces, Workplaces, Businesses, Schools, and Homes. Retrieved from https://www.cdc.gov/ coronavirus/2019-ncov/community/reopen-guidance.html.

4. Centre for Health Protection. (2020). Health Advice on Prevention of Coronavirus disease (COVID-19) for Properties Management (Interim). Retrieved from https://www.chp.gov.hk/files/pdf/advice_for_properti es_management_for_nid_of_public_health_significa nce_eng.pdf.

5. Department of Health. (2020). Coronavirus (COVID19) Environmental cleaning and disinfection principles for health and residential care facilities. Retrieved from https://www.health.gov.au/ resources/publications/coronavirus-covid-19-environmental-cleaning-and-disinfection-principles-forhealth-and-residential-care-facilities.

6. Department of Health. (2020). Environmental Cleaning in Non-Healthcare Settings. https://ww2. health.wa.gov.au/ /media/Files/Corporate/general \%20documents/Infectious\%20diseases/PDF/Corona virus/COVID19-Environmental-Cleaning-for-workplaces.pdf.

7. European Centre for Disease Prevention and Control. (2020). Disinfection of environments in healthcare and non-healthcare settings potentially contaminated with SARS-CoV-2.ECDC: Stockholm.

8. Fauci, A.S., Lane, H.C., \& Redfield, R. R. (2020). Covid-19 - Navigating the Uncharted. N Engl J Med, 382: 1268-69.

9. National Environment Agency. (2020). Interim Guidelines for Environmental Cleaning and Disinfection of Areas Exposed to Confirmed Case(s) of 2019 Novel Coronavirus (2019-nCoV) in NonHealthcare Commercial Premises. Retrieved from https://www.nea.gov.sg/our-services/public-cleanliness/environmental-cleaning-guidelines/guidelines/ guidelines-for-environmental-cleaning-and-disinfection.

10. Public Health England. (2020). Guidance - COVID19: cleaning in non-healthcare settings. Retrieved from https://www.gov.uk/government/publications/ covid-19-decontamination-in-non-healthcare-settings/covid-19-decontamination-in-non-healthcaresettings.

11. Queensland Government. (2020). COVID-19 cleaning and disinfection recommendations. Retrieved from https://www.qld.gov.au/health/ conditions/health-alerts/coronavirus-covid-19/information-for/industry-and-businesses/resources-andfact-sheets-for-industry/covid-19-cleaning-and-disinfection-recommendations.

12. Safe Work Australia. (2020). Cleaning to prevent the spread of COVID-19. Retrieved from https://www. safeworkaustralia.gov.au/covid-19-information-workplaces/cleaning-prevent-spread-covid-19.

13. World Health Organization. (2020). Modes of transmission of virus causing COVID-19: implications for IPC precaution recommendations. Scientific Brief, 27 March 2020, World Health Organization.

14. Wu, Y. C., Chen, C. S., \& Chan, Y. J. (2020). The outbreak of COVID-19: An overview. Journal of the Chinese Medical Association: JCMA, 83(3), 217220. https://doi.org/10.1097/JCMA.0000000000000 270 